\title{
Determining the causes behind the collapse of a small pelagic fishery using Bayesian population modeling
}

\author{
Fernando G. TABoAdA ${ }^{1}$ And Ricardo Anadón \\ Dpto. Biología de Organismos y Sistemas, University of Oviedo, C/Valentín Andrés Álvarez s/n, E33071 Oviedo, Spain
}

\begin{abstract}
Small pelagic fish species present complex dynamics that challenge population biologists and prevent effective management. Huge fluctuations in abundance have traditionally been associated with external environmental forcing on recruitment, exempting other processes from contributing to fisheries collapse. On the other hand, theory predicts that density dependence and overexploitation can increase the likelihood of population oscillations. Here, we combined nonlinear population modeling with Bayesian analysis to examine the importance of different regulatory mechanisms on the collapse of European anchovy (Engraulis encrasicolus) in the Bay of Biscay. The approach relied on detailed population data and in a careful characterization of changes in the environment experienced by anchovy early stages based mainly on satellite remote sensing. Alternative hypotheses about external forcing on recruitment determined prediction skill and provided alternative interpretations of the causes behind the collapse. Density dependence was weak and unable to generate huge oscillations. Instead, models considering changes in phytoplankton phenology or in larval drift presented the best prediction skill. Nevertheless, an extensive surrogate analysis showed that environmental fluctuations alone barely explain anchovy collapse without considering the impact of fishing. Our results highlight the effectiveness of a Bayesian approach to analyze the dynamics and collapse of managed populations.
\end{abstract}

Key words: Bay of Biscay; Bayesian analysis; European anchovy (Engraulis encrasicolus); fisheries collapse; population regulation; remote sensing; small pelagic fish.

\section{INTRODUCTION}

Small pelagic fish species support some of the most important fisheries around the world (Fréon et al. 2005). These fisheries are characterized by huge fluctuations in catches and yield that challenge effective management and long-term sustainability. Early maturation and short life span make populations of small pelagic fish species especially sensitive to fluctuations in environmental factors, including those related to human-induced climate change (Checkley et al. 2009). External forcing is usually invoked to explain the irregular dynamics observed in these species, although their maximum population growth rates make them good candidates to develop complex dynamics (Tuljapurkar et al. 1994). Put together, these ecological traits result in a practical inability to anticipate a failure in recruitment and to assess the potential impacts of fishing (Fréon et al. 2005). This feature is common to many other populations in which current modelling approaches provide little prediction ability (Ward et al. 2014). Indeed, it highlights a general need of integrative approaches for better population management and conservation (Hilborn and Mangel 1997).

Manuscript received 2 January 2015; revised 8 July 2015; accepted 4 August 2015; final version received 16 September 2015. Corresponding Editor: E. J. Ward.

${ }^{1}$ E-mail: fgtaboada@gmail.com
Population regulation in fish species usually operates at early stages and, like in many other species, results from the combined effect of both density-dependent and density-independent mechanisms (Bjørnstad and Grenfell 2001, Turchin 2003). Several nonexclusive and complementary hypotheses have been proposed to explain fluctuations in fish recruitment, although most of them are centered around three main themes (Cowan and Shaw 2002, Houde 2008); (1) the existence of a critical period when either food quantity or quality determines recruitment success through its effect on larval growth and survival; (2) the dependence of recruitment success on hydrographic conditions that modulate the dispersal or retention of planktonic eggs and larvae in nursery grounds, and (3) the importance of negative interactions with predators and competitors. The combination of these mechanisms leads to other hypotheses (Cury and Roy 1989, Bakun 1996). Determining whether any candidate explanation can shed light on the recruitment process is complicated by the difficulties associated with the study of early fish stages (i.e. widely but discontinuously distributed massive amounts of tiny eggs and larvae; Fuiman and Werner 2002). Nevertheless, the relative importance of different mechanisms can be inferred indirectly by studying how changes in the environment impact population dynamics (Hilborn and Mangel 1997, Turchin 2003).

We propose here a sequential approach to examine the importance of different regulatory mechanisms on 
the recent collapse of European anchovy (Engraulis encrasicolus L. 1758) in the Bay of Biscay. We derived first a set of environmental indices to represent the main candidate hypotheses postulated to explain fluctuations in the recruitment of small pelagic species. Then, we assessed the importance of both density-dependent and density-independent mechanisms of population regulation under a Bayesian framework by fitting a set of nonlinear, age-structured population models to detailed scientific survey data available for the population (ICES, 2012). Model structures considering different mechanisms were compared based on their ability to anticipate fluctuations in biomass and especially, on their ability to predict the collapse of the fishery. In the last step, we used highly ranked models to assess the likelihood of collapse under different assumptions about population regulation and exploitation. The methods proposed can be easily applied to other managed systems to illuminate complex population dynamics and to improve population management.

\section{Materials and Methods}

\section{European anchovy fisheries in the Bay of Biscay}

European anchovy, Engraulis encrasicolus L., is a small pelagic fish species (up to $20 \mathrm{~cm}$ length) widely distributed along the Mediterranean and eastern Atlantic coasts (Whitehead et al. 1988; further species information available online: www.fao.org/fishery/species/2106). It is a short-lived (usually does not exceed $3 \mathrm{yr}$ of age) and fast-growing species that reaches maturity during its first year of life. As other clupeoids, it is a planktivorous fish that forms large migrating schools preyed upon by a wide variety of predators, including other fish species, seabirds, and marine mammals. It is also extensively exploited for food and as live bait throughout its range.

Anchovy supports one of the most important fisheries in the Bay of Biscay (see Fig. 1 and Uriarte et al. 1996), where a small-scale fleet of purse-seiner and pelagic trawlers operates seasonally (Fig. 2). As in other small pelagics, anchovy annual catches fluctuate widely, with an almost 10-fold variation between good and bad years (average catch rate and range of $26[5-48] \times 10^{3} \mathrm{t}$ per year for the period 1970-2000; Fig. 2). A sudden decline in anchovy catches early in 2005 lead to the closure of the fishery until 2010, and resulted in important socioeconomic impacts (Vermard et al. 2008, Andrés and Prellezo 2012). The fishery was reopened in 2010 but a relatively low fishing quota was established, setting a constant harvest rate of $30 \%$ of the spawning stock biomass bounded to the interval $7-33 \times 10^{3} \mathrm{t}$ (ICES, 2012).

\section{Data sources and preparation}

Long-term scientific monitoring of anchovy fishery in the Bay of Biscay provides detailed catch at age statistics and abundance estimates for the period 1987-2011 (ICES, 2012). Each spring, spawning stock biomass at age is estimated using two different methods; the daily egg production method (Somarakis et al. 2004) and acoustic surveys (Massé 1996). Both surveys are carried over the southeastern portion of the Bay of Biscay and cover the main spring spawning aggregations (see ICES 2012 and the Appendices S1 and S2). It is important to note that we used these raw data to fit our models in order to deal directly with sampling error (e.g. Walters and Ludwig 1981, Brooks and Deroba 2015).

Fluctuations in anchovy recruitment are behind changes in anchovy abundance and fishery yield (age 1 recruits account for more than one-half of the annual catch biomass, 58.8\% [34.9-86.9\%, mean and range, 1987-2004; ICES 2012). Several environmental processes seem related to recruitment success. Weak upwelling intensity and water column stability in spring in the southeastern Bay of Biscay seem to favor larval dispersal and survival over the shelf (Allain et al. 2007, Borja et al. 2008). River discharge also seems to enhance larval survival by increasing water column stability and productivity (Bergeron et al. 2010), although the negative association found with the recruitment series points toward alternative mechanisms (Borja et al. 2008, Planque and Buffaz 2008). On the other hand, it has been suggested that open waters off the shelf might favor enhanced larval growth and survival by providing an environment where competition for resources and predation is less intense (Irigoien et al. 2007).

In order to assess the main candidate hypotheses proposed to explain environmentally driven fluctuations in recruitment (Appendix S2, Table S1), we assembled ancillary data from a variety of data sources, including (Table S2, Figs. S4 and S5 in Appendix S2): (1) wind vector data to derive Ekman transport, the number of calm periods (i.e. Lasker events, Peterman and Bradford 1987) and an index of turbulent mixing (Atlas et al. 2011); (2) abundance estimates of potential predators and competitors (ICCAT, 2013; ICES, 2013); (3) ocean color data to analyze changes in phytoplankton phenology and abundance (Feldman and McClain 2012); (4) time series of sea surface temperature (Reynolds et al. 2007; (5) river discharge time series (HYDRO, 2013); and (6) satellite altimetry to identify transport barriers (Le Traon et al. 1998, Shadden et al. 2005). For each candidate index, we considered different spatial domains and temporal windows of integration. We compared then different variants of the same index based on their relative ability to explain changes in point estimates of a larval survival index derived from ICES's (2012) stock assessment data (Platt et al. 2003). We favored the combination resulting in the best fit, but we took into consideration at the same time physical and biological constraints (see Appendix S3). The larval survival index presumes constant productivity and might be confounded by density-dependent effects and estimation errors, so we further examined the set of preselected environmental indices in a nonlinear context and using raw survey data. 


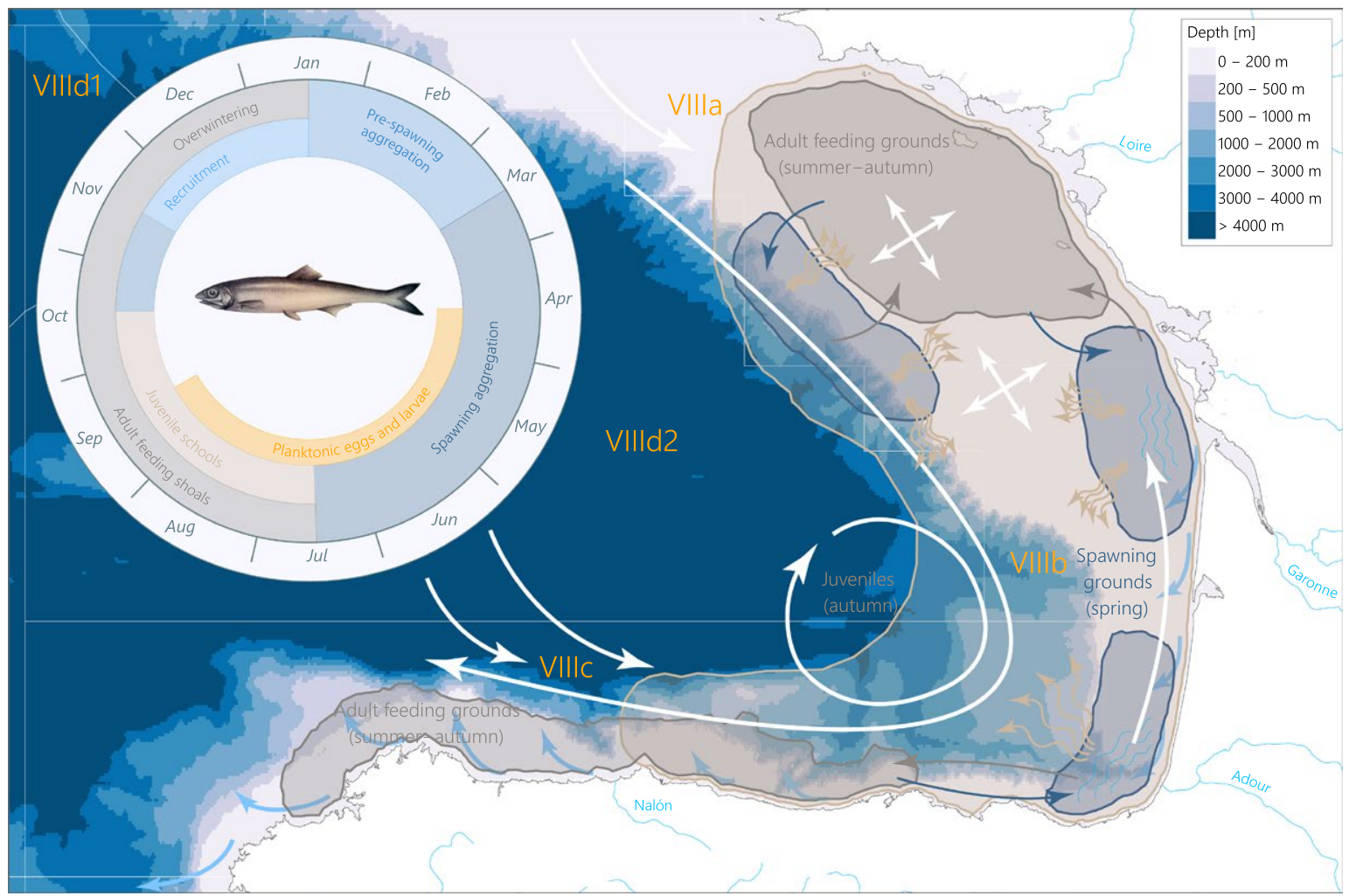

FIG. 1. Distribution and life cycle of European anchovy (Engraulis encrasicolus) in the Bay of Biscay (Uriarte et al. 1996; Irigoien et al. 2007, ICES, 2012). Different patches in the map represent the idealized distribution of juveniles and adults during the year. The main events in the annual cycle are summarized in the inset clock. European anchovy is a batch spawner with a long spawning season (April-August, Motos 1996). The main spawning grounds are associated with the mouth of Garonne and Adour rivers (Spain and France), although a third spawning aggregation located in the shelf break and composed mainly by older individuals is detected in some years (Motos et al. 1996). Fishers take advantage of these aggregations and, indeed, most catches are recorded in spring in coastal spawning grounds (Uriarte et al. 1996, see also Fig. 2). After spawning, eggs remain no more than three days floating near the surface before hatching a larva that spend 30-40 d in the plankton. Currents in the Bay of Biscay during the spawning season (white arrows, Charria et al. 2013) drift eggs and larvae away from spawning grounds, conditioning the distribution of juveniles (Koutsikopoulos and Le Cann 1996). The intensity of coastal upwelling and the presence of mesoscale features might also contribute to drift propagules away or to retain them close to the coast, as well as to modulate plankton productivity. Adults remain together following aggregation around the main spawning grounds in spring, forming large feeding shoals that migrate northward and westward along the coast (Uriarte et al. 1996). In late autumn, schools disaggregate and both adults and juveniles migrate to depth until the next spring, when anchovies $\sim 1$ yr old will be sufficiently mature to contribute spawning and recruit into the fishery massively. Bathymetric data from the GEBCO One Minute Grid, version 2.00 (UNESCO, Paris, France).

\section{Population model}

We modeled the dynamics of European anchovy in the Bay of Biscay using an age-structured biomass model including a nonlinear recruitment function and external environmental forcing on recruitment (Deriso 1980, Schnute 1985). Our approach was partially based on the models currently used to assess the status of the fishery and to establish total allowable catch (Ibaibarriaga et al. 2008, 2011). In this way, our aim was to model spawning stock biomass considering density-dependent and density-independent mechanisms of population regulation simultaneously.

The biomass of spawners at age $a$ in year $t, x_{t, a}$, was modeled at the time of biomass surveys $\left(\Delta t_{s}=0.375\right.$, i.e. 15 May; see Ibaibarriaga et al. 2008, 2011). The stock was modeled as a closed population in which changes in $x_{t, a}$ were only due to recruitment, the balance between growth and natural mortality (collapsed in a constant rate of biomass decrease or physiological mortality rate, $m)$, and monthly fishing $\left(f_{t, a}(s)\right.$, the catch rate at age $a$ at fractional time $s$ within the year; see Mertz and Myers 1996)

$$
x_{t, a}=\left(x_{t, a}^{i}-\int_{0}^{\Delta t_{s}} \mathrm{e}^{m s} f_{t, a}(s) \mathrm{d} s\right) \mathrm{e}^{-m \Delta t_{s}+u_{t, a}}
$$

where the biomass at the beginning of the year, $x_{t, a^{i}}$, decreases by fishing and natural mortality. Both population renewal and survival were subjected to demographic noise, represented by an unstructured, mean zero normally distributed process, $u_{t, a} \sim N\left(0, \sigma_{a}^{2}\right)$. Process noise variance differed and was considered a priori independent between age classes.

The model considered two age groups; age 1 individuals are new recruits entering the fishery at the 

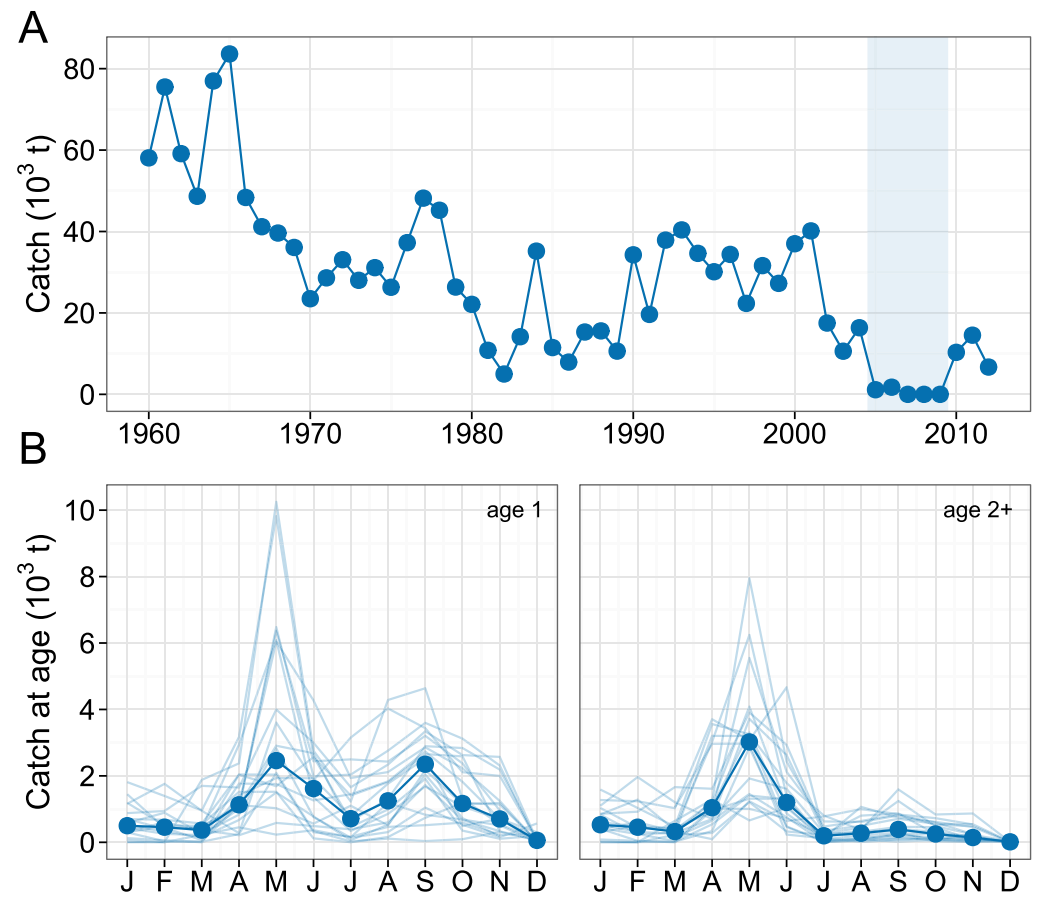

FIG. 2. Anchovy catches in the Bay of Biscay. (A) Time series of total catch [t] for the period 1960-2012. Small-scale purse seiners are responsible of most of the catch, which has declined steadily since the mid 1960's. There was a period of extraordinarily low catches in the mid 1980's and a collapse during the last decade that ended with the closure of the fishery in July 2005 (blue rectangle). The fishery was reopened in 2010, but a low fishing quota was established. (B) Seasonal catches [t] at age between 1987 and 2011. Fishing has a strong seasonal component, with catches concentrated on spawning grounds in the southeastern Bay of Biscay in spring and on feeding shoals in late summer and autumn (see Fig. 1). Recruits of the year predominate over older individuals in the catch throughout the year, especially during the second half. Data from ICES (2012); seasonal catches at age were derived from integrated monthly catch statistics by assuming a constant age structure during each half year.

beginning of each year $\left(x_{t, 1}^{i}\right)$, while the age $2+$ class includes recruits and older adults surviving from previous years $\left(x_{t, 2+}^{i}\right)$. In the latter case, the dynamics since spawning until the beginning of the next year were modeled by a constant rate decrease in biomass

$$
x_{t, 2+}^{i}=\sum_{a=1,2+}\left(x_{t-1, a}-\int_{\Delta t_{s}}^{1} \mathrm{e}^{m s} f_{t-1, a}(s) \mathrm{d} s\right) \mathrm{e}^{-m\left(1-\Delta t_{s}\right)} .
$$

Recruitment was considered a more complex process subjected to strong population regulation. Indeed, this phase embraces planktonic development and growth and it is usually associated with very high mortality rates (Houde 2002). Despite the prolonged reproductive season of European anchovy in the Bay of Biscay (Motos et al. 1996), population renewal was reduced to a single pulse of age 1 adults recruiting into the fishery at the beginning of each natural year $\left(x_{t, 1}^{i}\right)$. Individuals from both age classes were sexually mature at the time of the surveys and contributed to next-year recruitment with the same fecundity, assumptions justified to a great extent by available observations (Motos 1996).

The potential biomass of new recruits entering the fishery was related to spawning biomass in the previous year at the time of the surveys using a Deriso-Schnute stock-recruitment relationship (Deriso 1980, Schnute 1985).

$\mathrm{g}\left(x_{t-1, \cdot}\right)_{[0, \infty)}=\alpha x_{t-1, \cdot}\left(1-\beta \gamma x_{t-1, .}\right)^{1 / \gamma}, \quad x_{t-1, \cdot}=\sum_{a=1,2+} x_{t-1, a}$

where the strength of recruitment depends on the productivity parameter $\alpha$ [t of recruit per t of adult biomass]; the optimality parameter $\beta\left[1 / 10^{3}\right.$ t of adult biomass $]$; and the dimensionless recruitment limitation parameter $\gamma$. Note that both $\alpha$ and $\beta$ should be positive. This relation allows a great flexibility in the shape of the renewal function (Schnute 1985), including as special cases common stock-recruitment relationships like (1) the nonregulatory, constant productivity model (if $\gamma=-\infty$ ); (2) the compensatory but saturating Beverton and Holt (1957) function $(\gamma=-1)$; (3) the over compensatory Ricker (1954) recruitment function $(\gamma=0)$, and (4) the also over compensatory but symmetric Schaefer (1954) function $(\gamma=1)$. Note that the recruitment function does not allow for depensation.

The deterministic skeleton of this model gives rise to a rich variety of dynamics depending on the shape of the density dependent renewal function (Eq. 3), including complex cycles and chaos (Tuljapurkar et al. 
1994). We assessed the potential importance of density independent mechanisms by allowing interannual variation in the strength of recruitment. Potential population renewal Eq. 3 was modulated in this way by the effect of unstructured demographic noise (a pure stochastic component, i.e. Eq. 1), but also by structured perturbations due to environmental forcing on potential recruitment

$$
x_{t, 1}^{i}=\mathrm{g}\left(x_{t-1,}\right) \mathrm{e}^{\eta\left(z_{t-1}-z_{r e f}\right)}-\int_{\Delta t_{s}}^{1} f_{t-1,0}(s) \mathrm{d} s
$$

where the first term on the right-hand side represents potential recruitment and the second accounts for catches of age 0 juveniles during the fall of the year preceding recruitment (Uriarte et al. 1996). Environmental forcing had a multiplicative effect on expected recruitment that we assumed to occur before fishing. We assessed the potential effect of a set of environmental indices related to larval survival that represent different hypotheses about recruitment variation (Appendix S2: Table S1 Cowan and Shaw 2002, Houde 2008). Each index $z_{t}$ was standardized to mean zero and variance one before the analysis to ease comparisons among different covariates. The strength of the effect of each environmental factor on next-year recruitment was determined by the parameter $\eta$. The effect was proportional in a logarithmic scale to deviations from $z_{r e f}$, a reference level corresponding to an inflection point in the sign of the effect of a given covariate. This parameter is unidentifiable, so we redefined the productivity parameter in Eq. 3 as $\alpha^{\prime}=\alpha \mathrm{e}^{-\eta z_{\text {ref }}}$, which can be interpreted as fish productivity at average environmental conditions. To avoid further complexities, the effect of different covariates was assessed one at a time.

Monthly catch rate at age time series $\left(f_{t, a}(s)\right)$ were estimated from integrated monthly catch statistics and integrated catch-at-age data per semester by assuming a constant age structure (ICES, 2012). Catch-at-age data entered the model directly to include seasonal changes in fishing mortality for each age group by solving numerically the integral in Eqs. 1-4 (Mertz and Myers 1996). The model was completed with an estimate of spawning biomass in the first simulation year $(t=0 \equiv 1987), x_{0, a}$, necessary for model initialization. Model parameters and symbols are listed in Appendix S3: Table S1.

\section{Model fitting and inference}

The model was fitted to survey based estimates of spawning stock biomass, $y_{t, a, k}$, under a Bayesian framework (Robert 2001). Bayesian methods are ideally suited for the short and noisy time series that are common in ecology; they ease the use of mechanistic nonlinear models and they integrate different sources of uncertainty in a natural way, like observational noise and missing data, from parameter estimation to model-based predictions (Clark and Bjørnstad 2004, Cressie et al.
2009). We used a state-space representation and fitted the model combining Markov Chain and Sequential Monte Carlo Methods (i.e. a particle filter; the preferred method to fit nonlinear, state-space models; see West and Harrison 1997 and Doucet et al. 2001). This approach tries to reconstruct the latent or hidden Markov process $x_{t, a}$ (Eq. 1) based on abundance estimates available for the population for the period 1987-2011 (ICES, 2012). Depending on the year, only estimates based on the daily egg production method and/or based on acoustic surveys were available $(k=d e p m$, acst, respectively; see Appendix S1: Table S1). Recognizing the separation between observation and process allows a better estimation of both unknown states and model parameters (Carlin et al. 1992, West and Harrison 1997). In this way, the model can be formulated in state-space form by including an observation equation relating underlying state biomass and survey estimates

$$
\begin{array}{cc}
\log \left(x_{t, a}\right)=\log \left(h\left(\mathbf{x}_{t-1}\right)\right)+u_{t-1, a}, & u_{t-1, a} \sim N\left(0, \sigma_{a}^{2}\right), \\
\log \left(y_{t, a, k}\right)=\log \left(q_{k} x_{t, a}\right)+v_{t, k}, \quad & v_{t, k} \sim N\left(0, \tau_{k}^{2}\right)
\end{array}
$$

where in the state equation (Eq. 5), $h(\cdot)$ is a function updating states between years (i.e. the deterministic skeleton of Eq. 1). The observation equation (Eq. 6) includes an unknown detectability (i.e. catchability) coefficient, $q_{k}$, included to account for the potential bias of each sampling method. We assumed that depm observations were unbiased and fixed $q_{\text {depm }}$ to unity (Ibaibarriaga et al. 2008, 2011). Taking the natural logarithm results in normally distributed process $\left(u_{t}\right)$ and observation $\left(v_{t}\right)$ errors. Process noise propagates between years, whereas observation errors were regarded as independent.

Parameter estimation in state-space models usually proceeds in two sequential steps by conditioning alternately on estimates of model parameters or on estimates of the state process (West and Harrison 1997). Model parameters included in all cases detectabilities and observation variances for observation equations and a varying number of parameters for the process equation (see previous section and Appendix S4). In the case of models including the effect of the environment on recruitment, some of the covariates used lack data during the early years of the study period. During model fit, we combined estimates of the productivity parameter and of the strength of the environmental effect to impute missing covariate values. Each missing year was treated independently, assuming a normal prior with mean zero and variance one. Model fit began with randomly selected initial values and involved a total of 30000 iterations, with a burn-in of 20000 iterations that were discarded. The last 10000 samples were thinned to retrieve 1000 realizations of the estimated posterior distribution of states and parameters.

Model selection and inference proceeded by comparing the ability of models varying in structure and in 
the environmental effect considered to predict observed changes in stock biomass. In this way, we set as a benchmark a simple model that considered a constant environment ( $z_{t}=0$ for all $t$ ), and no density-dependent regulation of recruitment (i.e. constant productivity, $\gamma=-\infty$ in Eq. 2). This model was compared to models which included different environmental effects both with and without density-dependent recruitment. Model diagnostics were based on the predictive distribution of onestep-ahead predictions, which was derived directly from posterior parameter estimates. We estimated mean absolute deviations based on forecast errors in the natural log scale and Ando's (2007) Bayesian Predictive Information Criterion (BPIC; see also Ando 2010), an index that weights goodness of fit with model complexity like Akaike Information Criterion (AIC). BPIC values can be interpreted in a similar way; lower values are better and differences between models above two units are indicative of a reliable improvement in model fit. The main difference between BPIC and AIC is that goodness of fit is measured in the former in terms of the predictive likelihood, i.e. on how well the model makes predictions one step ahead in time.

Parameter estimates were also used to estimate the probability of collapse under scenarios differing in management practices and environmental variation. The experiment consisted in simulating a large set of surrogate time series $\left(4.2 \times 10^{6}\right)$, keeping fishing mortality levels proportional to the actual pattern of fishing pressure experienced by the population during the entire study period, but gradually reducing fishing pressure (see Appendix S4 in the Supplemental Material for further details). We ran the experiment for models with the best prediction skill, although we included a model assuming a constant environment (no structured forcing on recruitment) and a nonlinear Deriso-Schnute renewal function as a baseline. The models considered both environmental effects on recruitment and random perturbations in both recruitment and adult survival associated to estimated process noise (i.e. $\sigma_{1}$ and $\sigma_{2+}$ ). Differences in the response to reduced fishing pressure and in the overall risk of collapse under different scenarios might provide a clue of the importance of different processes (environmental and internal regulation vs. fishing) on the recent collapse of the fishery. Appendix S4 provides full details about model inference and a detailed account of the model fitting procedure, including pseudocodes (Appendix S3: Tables S1 and S2).

\section{RESUlTS}

\section{Model diagnostics and environmental effects on recruitment}

Different formulations of the age-structured model provided a good fit to anchovy spawning stock biomass in terms of distributional assumptions (i.e. uncorrelated and normally distributed standard and forecast residuals).
Posterior parameter estimates of initial population sizes ( $x_{0, a}$, with age $a=1,2+$ ), adult physiological mortality rate $(m)$ and process noise on adult survival $\left(\sigma_{2+}\right)$ remained relatively constant among different model formulations (coefficient of variation, CV $<0.30$; see also Appendix S4: Table S1). According to these estimates, natural mortality alone might cause a decrease of $40 \%$ in anchovy adult biomass during an average year $\left(m=0.52 \mathrm{yr}^{-1}[0.26,0.73]\right.$; median and 90\% quantile-based credible intervals), although the impact of process noise on adult survival was also relatively important $\left(\sigma_{2+}=0.59[0.39,0.91]\right)$.

Assumptions about recruitment determined model dynamics and resulted in a clear hierarchy among candidate models (Table 1). In almost all cases, the inclusion of a nonlinear recruitment function improved prediction skill, although local stability analysis suggested a very low likelihood of deterministic complex dynamics (Appendices S3 and S4 and Appendix S4: Table S2). Indeed, prediction skill depended on how external forcing on larval survival entered the model and thus, on the ability of different environmental indices to reduce unstructured process noise on expected recruitment $\left(\sigma_{1}\right.$; Appendix S4: Table $\mathrm{S} 2$ ). The assessment clearly dismissed some potential mechanisms; diagnostics for models considering indices related to natural enemies or river discharge were similar to models considering random, unstructured environment forcing (Table 1). In all these models, including a DerisoSchnute renewal function resulted in highly nonlinear recruitment curves that improved skill considerably (Fig. 3). In general, these curves also presented a steeper initial slope, a feature that might be taken as an indicator of an higher recovery potential for the fishery. Nevertheless, it is important to note that this effect was most remarkable in the models with lower prediction skill.

The models with the greatest ability to anticipate fluctuations in recruitment included indices that can be grouped around two main mechanisms (Table 1 and Appendix S2); (1) enhanced larval survival when anchovy spawning match calm conditions over the Aquitanian shelf (advanced plankton phenology or transport barriers of low magnitude), and (2) a negative effect of strong winds during summer in the Armorican shelf (increased Ekman transport and turbulence, colder temperatures, or a reduced number of Lasker events). Models in the first group presented the best prediction skill, although the estimation of missing covariate values weighted down them in terms of parsimony. Unlike most models, the inclusion of a nonlinear recruitment function resulted in a negligible improvement or even in a deterioration of skill in the first group. Within the second group, the model considering summer Ekman transport was preferred by the Bayesian Prediction Information Criterion (BPIC). Including a nonlinear recruitment function increased prediction skill slightly, although not during the year of the collapse. Models including Ekman transport, plankton phenology, and transport barriers provided the best prediction skill and were retained for further scrutiny (Fig. 4). We used the variant including 
TABLE 1. Model diagnostics for the age structured models fitted to anchovy abundance data.

\begin{tabular}{|c|c|c|c|c|c|c|c|c|}
\hline & \multicolumn{4}{|c|}{ Constant productivity } & \multicolumn{4}{|c|}{ Deriso-Schnute recruitment function } \\
\hline & $n_{\theta}$ & $B P I C$ & $\sum\left|e_{t, a, k}\right| / n$ & $\sum\left|e_{2005, a, k}\right| / n$ & $n_{\theta}$ & $B P I C$ & $\sum\left|e_{t, a, k}\right| / n$ & $\sum\left|e_{2005, a, k}\right| / n$ \\
\hline \multicolumn{9}{|l|}{ Benchmark models } \\
\hline $\begin{array}{l}\text { Constant } \\
\text { environment }\end{array}$ & 8 & 252.8 & $1.04[0.80,1.38]$ & $3.94[2.92,5.24]$ & 10 & 238.9 & $0.74[0.68,0.86]$ & $4.73[4.26,5.49]$ \\
\hline \multicolumn{9}{|c|}{ Spring conditions over the Aquitanian shelf } \\
\hline $\begin{array}{l}\text { Plankton } \\
\text { phenology }\end{array}$ & 20 & 224.4 & $0.39[0.29,0.54]$ & $0.48[0.17,1.12]$ & 22 & 231.2 & $0.40[0.31,0.56]$ & $0.60[0.25,1.32]$ \\
\hline $\begin{array}{c}\text { Transport } \\
\text { barriers }\end{array}$ & 15 & 217.5 & $0.43[0.34,0.58]$ & $0.86[0.46,1.49]$ & 17 & 218.6 & $0.40[0.31,0.52]$ & $1.00[0.59,1.64]$ \\
\hline River discharge & 9 & 246.1 & $0.82[0.67,1.07]$ & $2.59[1.86,3.75]$ & 11 & 239.7 & $0.73[0.65,0.87]$ & $4.14[2.92,5.16]$ \\
\hline \multicolumn{9}{|c|}{ Summer conditions over the Armorican shelf } \\
\hline Ekman transport & 10 & 214.2 & $0.51[0.42,0.65]$ & $0.42[0.14,0.95]$ & 12 & 215.2 & $0.47[0.39,0.58]$ & $0.59[0.23,1.22]$ \\
\hline Lasker events & 10 & 239.2 & $0.74[0.61,0.95]$ & $1.76[1.13,2.73]$ & 12 & 238.1 & $0.67[0.58,0.83]$ & $2.21[1.40,3.47]$ \\
\hline Temperature & 9 & 238.7 & $0.72[0.60,0.94]$ & $3.37[2.52,4.57]$ & 11 & 240.7 & $0.68[0.57,0.85]$ & $3.88[2.92,4.98]$ \\
\hline Turbulence & 10 & 229.0 & $0.70[0.57,0.91]$ & $2.09[1.62,2.92]$ & 12 & 231.8 & $0.59[0.49,0.72]$ & $3.26[2.37,4.41]$ \\
\hline \multicolumn{9}{|l|}{ Natural enemies } \\
\hline Horse mackerel & 9 & 253.7 & $0.87[0.70,1.16]$ & $3.61[2.68,4.96]$ & 11 & 241.5 & $0.78[0.68,0.97]$ & $4.48[3.66,5.22]$ \\
\hline Mackerel & 9 & 256.6 & $0.95[0.76,1.27]$ & $3.45[2.37,4.80]$ & 11 & 237.2 & $0.69[0.63,0.81]$ & $4.31[3.77,4.97]$ \\
\hline Sardine & 9 & 253.4 & $1.01[0.82,1.28]$ & $4.54[3.13,6.13]$ & 11 & 241.6 & $0.75[0.67,0.88]$ & $5.17[3.64,6.37]$ \\
\hline Hake & 9 & 255.8 & $1.00[0.80,1.26]$ & $3.73[2.61,4.90]$ & 11 & 240.9 & $0.81[0.66,0.99]$ & $4.35[3.23,5.38]$ \\
\hline Blue whiting & 9 & 250.7 & $0.90[0.74,1.19]$ & $2.66[1.98,3.79]$ & 11 & 239.7 & $0.74[0.67,0.86]$ & $4.30[3.46,5.40]$ \\
\hline Albacore tuna & 11 & 259.3 & $0.98[0.77,1.28]$ & $3.69[2.64,4.96]$ & 13 & 242.0 & $0.76[0.67,0.93]$ & $4.94[4.21,6.14]$ \\
\hline
\end{tabular}

Notes: As detailed in Methods: Model fitting and inference, model selection was based on Ando's (2010) Bayesian Predictive Information Criterion (BPIC) and on mean absolute deviations. BPIC balances model fit and model complexity, which is measured as the number of parameters, $n_{\theta}$. Lower BPIC values correspond to better, more parsimonious models; differences above two units among models are indicative of a reliable improvement in model fit. Absolute deviations were estimated based on forecast errors in the natural $\log$ scale $\left(e_{t, a, k}=\log q_{k} x_{t, a}^{*}-\log y_{t, a, k}\right)$. We focused on the average of these absolute deviations for all years $\left(\sum \mid e_{t, a, k} / n\right)$, but also on the year when the fishery collapsed $(t=2005)$. A mean absolute deviation value of 0.7 means that, on average, observed abundances and the distribution of one-step-ahead predictions are within a factor of two among each other. The diagnostics for the preferred models are highlighted in boldface. Each row corresponds to a different type of environmental effect on recruitment, with entries on the left half corresponding to models assuming Constant productivity and models on the right corresponding to models with a nonlinear, Deriso-Schnute recruitment function. Models were further grouped depending on the nature of the environmental index related to larval survival, distinguishing; (1) Benchmark models with no environmental effect; (2) and (3) models including indices related to environmental conditions over the Aquitanian shelf in spring, or over the Armorican shelf in summer; and (4) models considering the impact of Natural enemies like fish predators and competitors. Model diagnostics were summarized by their median and quantile-based 90\% credible intervals (brackets). Appendices S3 and S4 provide further details and model diagnostics.

a nonlinear renewal function in all cases except for plankton phenology, where this choice leads to lower skill and unrealistic equilibrium population sizes (Appendix S4: Table S2). According to the preferred models, recruitment at low population sizes is close to previous year spawning biomass during an average year. These models also agreed in predicting a strong negative effect of the environment on the survival of recruits the year prior to the collapse (Fig. D1).

\section{Fishing, environmental variability, and anchovy collapse}

Despite the assessment of different models revealed a leading role of environmental forcing on determining fluctuations in anchovy biomass, it did not clarify why the population collapsed in 2005. To elucidate this issue, we ran an extensive simulation experiment to assess model based predictions about the impact of fishing on the probability of collapse. The experiment was based upon the analysis of surrogate time series and revealed a clear connection between fishing pressure and the recent collapse of the anchovy fishery in the Bay of Biscay (Fig. 5). According to our simulations and for all models (including the benchmark model with no environmental forcing on recruitment), a 50\% reduction in fishing pressure would have decreased the risk of collapse by $69-89 \%$ with respect to the risk associated to the actual pattern of fishing mortality experienced by the population during the study period. Nevertheless, the most important differences were related to how likely was the collapse under different model assumptions. Again, these differences depended to a great extent on assumptions related to recruitment regulation and, specifically, to the identity of the environmental covariate affecting recruitment rather than to the type of renewal function specified (i.e. linear or nonlinear). In this way, the contrast between predictions by the benchmark reference model and predictions by models including an external covariate highlighted clear differences in model predictions regarding the causes of the collapse (Fig. 5). 

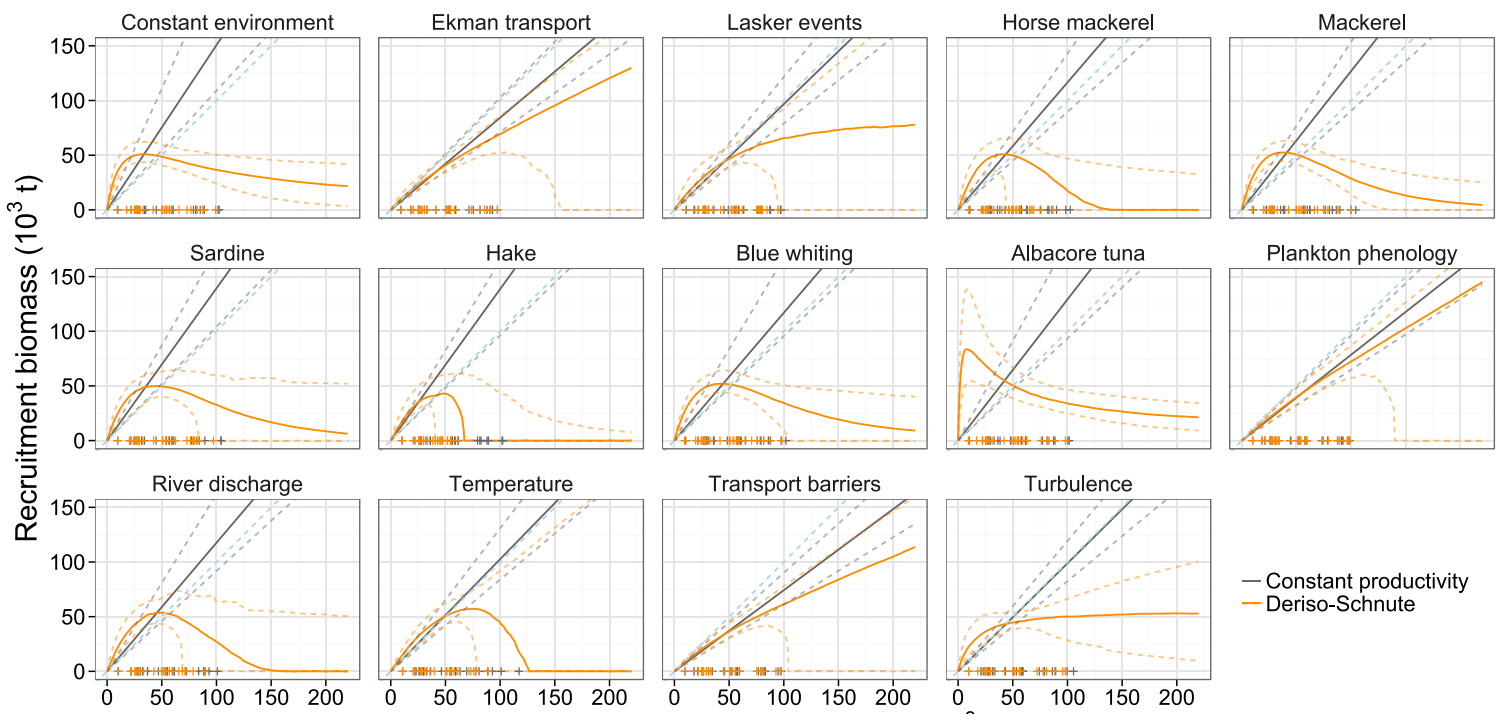

Blue whiting

Albacore tuna
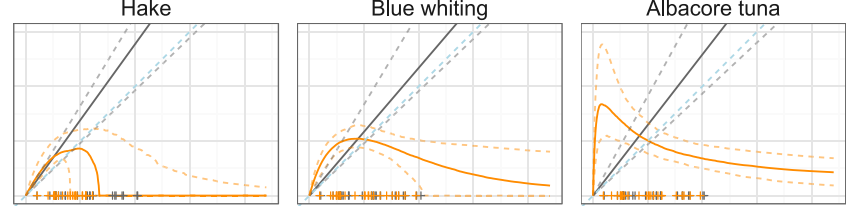

Plankton phenology
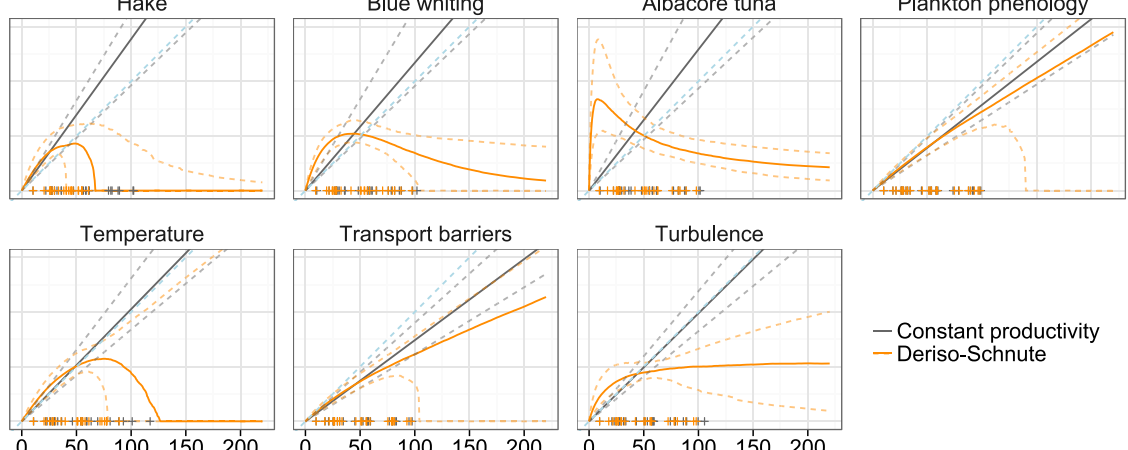

Transport barriers
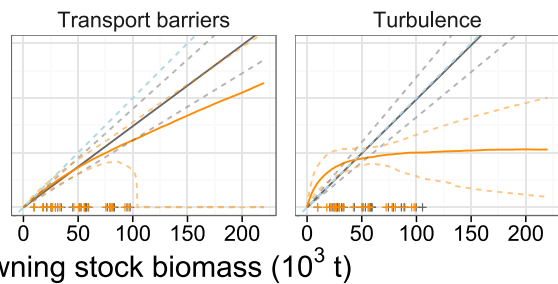

\section{- Constant productivity}

- Deriso-Schnute

FIG. 3. Posterior estimates of the recruitment function for different model structures (Eq. 2, median and $90 \%$ credible intervals; CI). Each panel presents estimates for models with the same environmental forcing but differing in the recruitment function fitted (constant productivity or Deriso-Schnute). Posterior median estimates of spawning stock biomass for each year are included on the abscissa. Differences in the shape of estimated recruitment functions reflect changes in the importance of density dependence and in the potential of recovery at low densities, arising in both cases from different assumptions about model structure. The dashed blue line corresponds to a recruitment level equal to previous-year spawning stock biomass [1:1].

Under the assumptions posed by the reference model (no structured effect of the environment on recruitment) the collapse might be interpreted as a very rare event due to the huge noise associated with recruitment (the estimated probability of a collapse with actual fishing rates was of $0.10[0.06,0.15]$, median and quantile-based $50 \%$ credible intervals). On the other hand, models with a better ability to predict changes in recruitment presented a strong response to changes in fishing pressure, moving from a nil or very low likelihood of collapse to relatively high chances as fishing pressure increased. This pattern cannot be interpreted as a consequence of exceptionally high, random perturbations in recruitment (process noise in recruitment was indeed much lower for these models, e.g. $\frac{\sigma_{1, e n v}}{\sigma_{1, \text { ref }}}=0.61[0.39,0.94]$; median and $90 \%$ quantilebased interval). All models presented a nonlinear sensitivity to reduced fishing pressure (Fig. 5). For instance, the model considering plankton phenology, which presented the best skill for the year of the collapse (Table 1), predicted a higher baseline level for the probability of collapse that increased at least 10 -fold as fishing pressure increased (from $0.03[0.00,0.08]$ with no fishing to 0.67 $[0.59,0.74]$ for actual fishing mortality rates).

\section{Discussion}

Anchovy dynamics in the Bay of Biscay seem to be regulated mainly through external environmental forcing on recruitment and perturbed by unstructured demographic noise. As a consequence, the combined effect of natural fluctuations of the environment and fishing mortality increases the risk of collapse of the fishery. According to our results, we identified two major groups of environmental processes with a great ability to anticipate recruitment success or failure; (1) larval survival is enhanced when anchovy spawning match calm conditions over the Aquitanian shelf, coinciding with an advanced timing of the bloom or the lack of strong transport barriers, and (2) strong winds during summer in the Armorican shelf exert a negative effect on recruitment, especially when summer Ekman transport along the coast is above average. These effects point directly to Hjort (1914)-Cushing's (1990) matchmismatch and Iles and Sinclair's (1982) member/vagrant hypotheses. Previous correlative studies also invoked upwelling and calm conditions to explain changes in anchovy recruitment success (Allain et al. 2007, Borja et al. 2008), although the timings and locations reported in these studies failed to explain fluctuations in recruitment within our dynamic model. Our results allowed us to discard other mechanisms, including opportunity windows associated with river discharge, the detrimental effect of natural enemies, and strong density-dependent recruitment regulation. Taken together, these results lead us to propose an alternative, testable framework for anchovy recruitment in the Bay of Biscay.

According to our results, the strength of anchovy recruitment involves several key events and processes. First, although we detected weak density-dependent regulation on population renewal, average recruitment was a linear or weakly nonlinear function of previousyear spawning biomass. The dependence of potential 

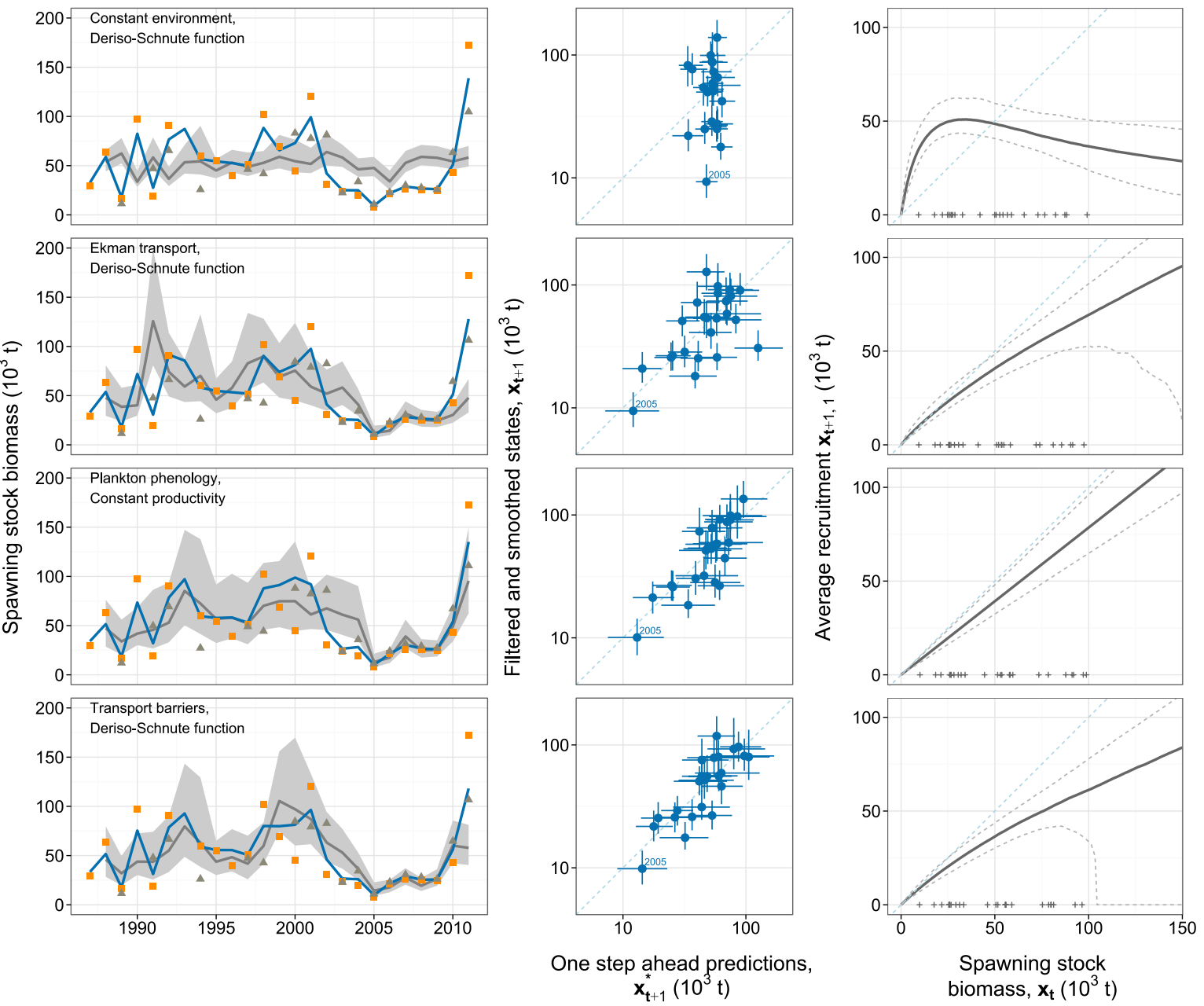

FIG. 4. Summary of model fits on spawning stock biomass $\left[10^{3} \mathrm{t}\right]$. Results are presented for models with no environmental effect on recruitment and for models providing the best prediction skill; i.e. those including the effect of indexes representing Ekman transport, plankton phenology, or transport barriers. We selected the model with a Deriso-Schnute renewal function in all cases except for plankton phenology, in which average recruitment was proportional to spawning biomass. Panels in the first column present observations for acoustic (gray triangles) and daily egg production methods (orange squares) corrected by estimated detectabilities; filtered and smoothed states (blue line), and one step ahead predictions (gray line; the shaded area correspond to quantile based $90 \%$ CI). Panels in the central second column are scatter plots of one-step ahead predictions vs. filtered and smoothed states (i.e. the scatter in this plot represents process variance; the dashed blue line corresponds to a perfect fit [1:1]). Note that the plots present $\log _{10}$ transformed estimates and that lines around the dots cover $90 \%$ CI. The third column presents plots with posterior estimates of the renewal function (median and quantile-based $90 \%$ CI represented by the thick gray line and the dashed gray lines, respectively). Filtered and smoothed states are model based estimates of actual population size that integrate uncertainty in observations and model parameters. A good model is that where filtered and smoothed estimates present a low uncertainty and can be predicted ahead in time accurately. The crosses in the abscissa correspond to the posterior median of filtered and smoothed states. The dashed blue line corresponds to a recruitment level equal to previous year spawning stock biomass [1:1].

production on previous year abundance introduces a certain degree of memory in anchovy dynamics, extending in time the effect of external perturbations like fishing or fluctuations in recruitment. According to our model, this sets an initial constraint on adult biomass and in the production of future recruits. Then, either of the two candidate mechanisms cited previously can be invoked to explain how environmental conditions might modulate recruitment success. A first alternative is that spring conditions in the southeast determine recruitment strength by enhancing or decreasing early larval survival, probably by modifying their trophic environment. Part of the remaining anchovy larvae might be drifted northward and will meet in some years larvae from the secondary spawning peak in the Armorican shelf. This secondary peak is composed by larger adults with higher fecundity that aggregate for spawning along the shelf break (Motos et al. 1996). The success of these anchovy recruits might be quite sensitive to a detrimental effect of seaward larval drift associated with summer upwelling. Both scenarios contrast with the recent appeal to the advantageous effect of larval drift to open waters 


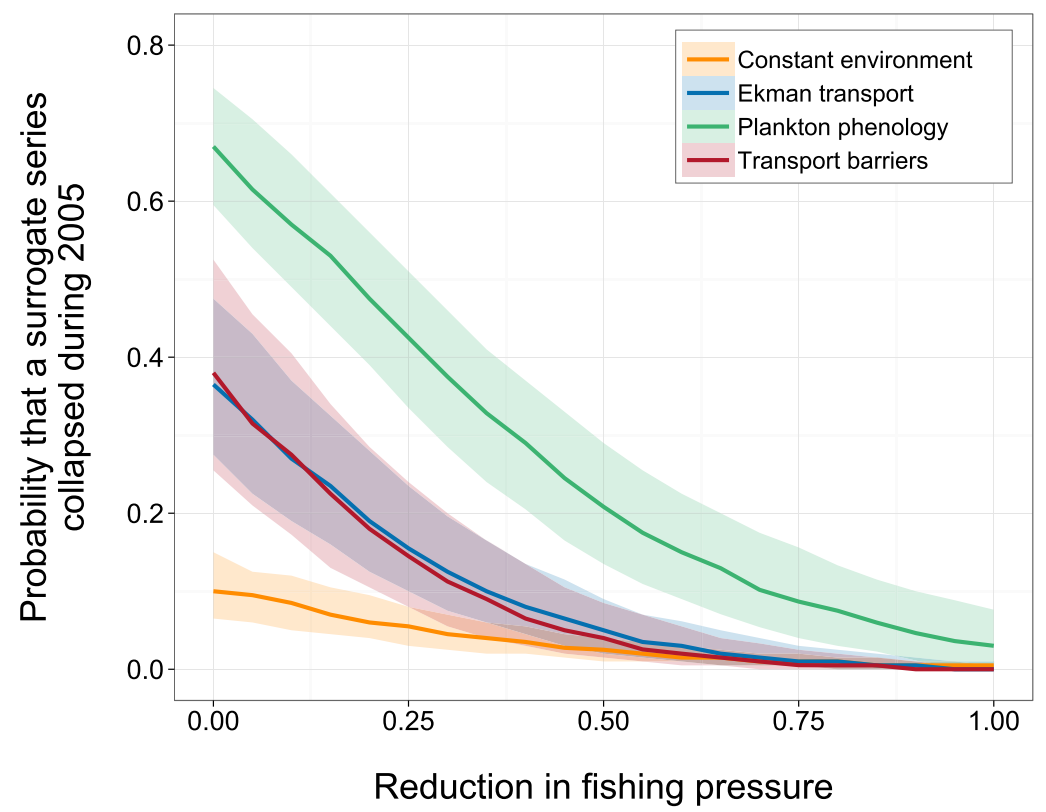

FIG. 5. Summary of surrogate analysis of anchovy collapse in the Bay of Biscay. The graph presents changes in the probability that a surrogate time series collapsed in 2005 as a function of fishing pressure (from realized fishing pressure [0.0] to no fishing [1.0]) for the same models presented in Fig. 4. The central line correspond to the median and the shaded ribbon to $50 \%$ quantile-based credible intervals; this confidence level was preferred to avoid the long tails associated with the distribution of these statistics. Results are presented for the best-performing models, that considered the effect of the following covariates on recruitment: Ekman transport, plankton phenology, and transport barriers (see Model diagnostics and environmental effects on recruitment for further details). The graph also presents estimates derived from a reference model considering a constant environment with no structured environmental effect on recruitment and that presented a poor performance (note that the model includes nevertheless process noise). See Appendix S4 for further details about the experiment.

(Irigoien et al. 2007), an alternative that found no support in our analysis of changes in anchovy environment. We cannot clarify whether any of the two proposed mechanisms is actually working or if any of the two just echoes the other. Indeed, our models considered only one environmental forcing mechanism at a time (e.g. see Fernandes et al. 2015), and they ignored other processes that might potentially affect recruitment, like changes in adult spawning behavior and body condition (Motos 1996). Although solving these questions is beyond this study, our results highlight the importance of early spring events in the southeast and late spring recruitment in the Armorican shelf, pointing respectively to trophic interactions and larval advection as alternative mechanisms that can be tested in the field.

The second main result of our study deals with the potential role of overfishing in the collapse of anchovy in the Bay of Biscay in 2005. Surrogate analysis of models incorporating different assumptions about recruitment regulation revealed an increased risk of collapse associated with increases in fishing pressure. Although this response varied depending on the environmental factor affecting recruitment, overfishing was favored in all cases over alternative explanations involving random or structured environmental perturbations of recruitment and adult survival. In this way, it reveals the leading role of fishing in promoting the collapse of fisheries of small pelagic species (Fréon et al. 2005). This result has important implications for fisheries management and leads us to paraphrase Connell (1980) and invoke a "ghost of overexploitation past" to explain reduced anchovy yields during the 1980's and the last decade in the Bay of Biscay. Historical catch records doubling recent levels provide a clue pointing in this direction, suggesting that fishing has prevented the population to reach the abundance levels needed to avoid an eventual collapse in case of a failure in recruitment. As an aside, reduced abundance associated with overfishing can also explain why we cannot detect strong density-dependent effects (e.g. Dennis and Taper 1994), especially given that natural predators may have already been reduced to low abundances (Jackson et al. 2001). The same declines have been observed in other aquatic and terrestrial ecosystems (Estes et al. 2011), suggesting a major limitation to determining the actual importance of ecological interactions in the wild.

In a more general context, our study highlighted the need to incorporate a careful assessment of environmental effects in population dynamics studies targeting the causes behind fluctuations in abundance (Anderson et al. 2008, Shelton and Mangel 2011). Our results and conclusions would have been very different if we had chosen to ignore this step. Assumptions about external forcing affected the ranking of the predictive ability of different models, as well as inferences about the importance of density dependence and the potential for fishery 
recovery. These factors need to be accounted for to understand how management actions could impact population dynamics, especially considering that current modeling approaches present, in general, low prediction ability (Ward et al. 2014). Indeed, this issue is not restricted to exploited species and might become a critical aspect in the case of assessments of extinction risk in endangered species (e.g. Bakker et al. 2009). An analysis like the one presented here was possible thanks to recent developments in Bayesian nonlinear time series analysis (West and Harrison 1997, Doucet et al. 2001, Kantas et al. 2009). The approach can be easily modified and applied to other exploited systems, and it can be extended to assess different management scenarios as well as the impact of projected changes in the environment. Indeed, this study provides just a glimpse of the advantages that the Bayesian framework can bring to population ecology and resource management (Cressie et al. 2009). The approach relied as well on long-term physical and biological databases. Continued monitoring and improved model based assessments is the key to solve the long standing puzzle of the causes of population fluctuations, as well as the only way to ensure a sustainable exploitation of small pelagic fisheries.

\section{ACKNOWLEDGMENTS}

We thank the International Commission for the Exploration of the Sea (ICES), especially the Working Group on Southern Horse Mackerel, Anchovy and Sardine (WGHANSA), and the International Commission for the Conservation of Atlantic Tunas (ICCAT), for the production and availability of the fish biomass data used in this study. We also thank NASA Ocean Biology Processing Group and Physical Oceanography Distributed Active Archive Center (PO.DAAC), NOAA National Climatic Data Center (NCDC), and the Centre Nationel d'Etudes Spatiales (CNES) for the availability, production and maintenance of the remote sensing data employed. The altimeter products were produced by Ssalto/Duacs and distributed by Aviso with support from CNES. We also thank the production and availability of river discharge data to the Directions Régionales de l'Environnement, de l'Aménagement et du Logement (DREAL) and Banque HYDRO, Ministère de L'Écologie, du Developpement Durable et de L'Énergie, France. J. A. Sostres provided support and helped us with data management and analyses. I. Martínez, C.L. Cáceres, J. Höfer, A. Molina, C. A. Stock, and three anonymous reviewers provided valuable comments and discussion on earlier versions of the manuscript. This work has been supported by project ECOANCHOA, Dirección General de Pesca, Gobierno del Principado de Asturias.

\section{Literature Cited}

Allain, G., P. Petitgas, and P. Lazure. 2007. The influence of environment and spawning distribution on the survival of anchovy (Engraulis encrasicolus) larvae in the Bay of Biscay (NE Atlantic) investigated by biophysical simulations. Fisheries Oceanography 16:506-514.

Anderson, C. N. K., C.-H. Hsieh, S. A. Sandin, R. Hewitt, A. Hollowed, J. Beddington, R. M. May, and G. Sugihara. 2008. Why fishing magnifies fluctuations in fish abundance. Nature 452:835-839.
Ando, T. 2007. Bayesian predictive information criterion for the evaluation of hierarchical bayesian and empirical bayes models. Biometrika 94:443-458.

Ando, T. 2010. Bayesian model selection and statistical modeling, First edition. CRC Press, Boca Raton, Florida, USA.

Andrés, M., and R. Prellezo. 2012. Measuring the adaptability of fleet segments to a fishing ban: the case of the bay of biscay anchovy fishery. Aquatic Living Resources 25:205-214.

Atlas, R., R. N. Hoffman, J. Ardizzone, S. M. Leidner, J. C. Jusem, D. K. Smith, and D. Gombos. 2011. A crosscalibrated, multiplatform ocean surface wind velocity product for meteorological and oceanographic applications. Bulleting of the American Meteorological Society 92:157-174.

Bakker, V. J., D. F. Doak, G. W. Roemer, D. K. Garcelon, T. J. Coonan, S. A. Morrison, C. Lynch, K. Ralls, and R. Shaw. 2009. Incorporating ecological drivers and uncertainty into a demographic population viability analysis for the island fox. Ecological Monographs 79:77-108.

Bakun, A. 1996. Patterns in the ocean: ocean processes and marine population dynamics. Univ. California Sea Grant, San Diego, California, USA, in cooperation with Centro de Investigaciones Biológicas de Noroeste, La Paz, Baja California Sur, México.

Bergeron, J.-P., D. Delmas, and N. Koueta. 2010. Do river discharge rates drive the overall functioning of the pelagic ecosystem over the continental shelf of the Bay of Biscay (NE Atlantic)? A comparison of two contrasting years with special reference to anchovy (Engraulis encrasicolus L.) nutritional state. Journal of Oceanography 66:621-631.

Beverton, R. J. H., and S. J. Holt. 1957. On the dynamics of exploited fish populations. First edition. Fishery Investigations Series II. Ministry of Agriculture, Fisheries and Food, London, UK.

Bjørnstad, O. N., and B. T. Grenfell. 2001. Noisy clockwork: time series analysis of population fluctuations in animals. Science 293:638-643.

Borja, Á., A. Fontán, J. Saénz, and V. Valencia. 2008. Climate, oceanography, and recruitment: the case of the Bay of Biscay anchovy (Engraulis encrasicolus). Fisheries Oceanography 17:477-493.

Brooks, E. N., and J. J. Deroba. 2015. When "data" are not data: the pitfalls of post hoc analyses that use stock assessment model output. Canadian Journal of Fisheries and Aquatic Sciences 72:634-641.

Carlin, B. P., N. G. Polson, and D. S. Stoffer. 1992. A Monte Carlo approach to nonnormal and nonlinear statespace modeling. Journal of the American Statistical Association 87:493-500.

Charria, G., P. Lazure, B. L. Cann, A. Serpette, G. Reverdin, S. Louazel, F. Batifoulier, F. Dumas, A. Pichon, and Y. Morel. 2013. Surface layer circulation derived from Lagrangian drifters in the Bay of Biscay. Journal of Marine Systems 109-110(Supplement):S60-S76.

Checkley, D., J. Alheit, Y. Oozeki, and C. Roy, editors. 2009. Climate change and small pelagic fish, First edition. Cambridge University Press, Cambridge, UK.

Clark, J. S., and O. N. Bjørnstad. 2004. Population time series: process variability, observation errors, missing values, lags, and hidden states. Ecology 85:3140-3150.

Connell, J. H. 1980. Diversity and the coevolution of competitors, or the Ghost of Competition Past. Oikos 35:131-138.

Cowan, J. H. and R. F. Shaw. 2002. Recruitment. Pages 88-111. in L. A. Fuiman, and R. G. Werner, editors. Fishery science. First edition. Blackwell Publishing, Oxford, UK. 
Cressie, N., C. A. Calder, J. S. Clark, J. M. V. Hoef, and C. K. Wikle. 2009. Accounting for uncertainty in ecological analysis: the strengths and limitations of hierarchical statistical modeling. Ecological Applications 19:553-570.

Cury, P., and C. Roy. 1989. Optimal environmental window and pelagic fish recruitment success in upwelling areas. Canadian Journal of Fisheries and Aquatic Sciences 46:670-680.

Cushing, D. 1990. Plankton production and year-class strength in fish populations: an update of the Match/Mismatch Hypothesis. Advances in Marine Biology 26:249-293.

Dennis, B., and M. L. Taper. 1994. Density dependence in time series observations of natural populations: estimation and testing. Ecological Monographs 64:205-224.

Deriso, R. B. 1980. Harvesting strategies and parameter estimation for an age-structured model. Canadian Journal of Fisheries and Aquatic Sciences 37:268-282.

Doucet, A., N. de Freitas, and N. Gordon, editors. 2001. Sequential Monte Carlo methods in practice. SpringerVerlag, New York, New York, USA.

Estes, J. A., et al. 2011. Trophic downgrading of planet earth. Science 333:301-306.

Feldman, G. C. and C. R. McClain. 2012. SeaWiFS Reprocessing 2010.0 and Aqua MODIS Reprocessing 2013.0. in N. Kuring, and S. W. Bailey, editors. Ocean color web. NASA Goddard Space Flight Center. Accessed May 2013, http://oceancolor.gsfc.nasa.gov/.

Fernandes, J. A., X. Irigoien, J. A. Lozano, I. Inza, N. Goikoetxea, and A. Pérez. 2015. Evaluating machine-learning techniques for recruitment forecasting of seven North East Atlantic fish species. Ecological Informatics 25:35-42.

Fréon, P., P. Cury, L. Shannon, and C. Roy. 2005. Sustainable exploitation of small pelagic fish stocks challenged by environmental and ecosystems changes: a review. Bulletin of Marine Science 76:385-462.

Fuiman, L. A., and R. G. Werner, editors. 2002. Fishery science, First edition. Blackwell Publishing, Oxford, UK.

Hilborn, R. and M. Mangel. 1997. The Ecological detective. Confronting models with data, volume 28 of Monographs in Population Biology. First edition. Princeton University Press, Princeton, New Jersey, USA.

Hjort, J. 1914. Fluctuations in the great fisheries of northern Europe viewed in the light of biological research. Rapports et Procs-Verbaux des Reunions, Conseil International; pour I'Exploration de la Mer 20:1-228.

Houde, E. D. 2002. Mortality. Pages 64-87. in L. A. Fuiman, and R. G. Werner, editors. Fishery science. First edition. Blackwell Publishing, Oxford, UK.

Houde, E. D. 2008. Emerging from Hjort's shadow. Journal of the Northwest Atlantic Fishery Science 41:53-70.

HYDRO. 2013. Discharge of river Garonne at Tonneins (DREAL Midi-Pyrénées. Banque Hydro, Ministére de l'Écologie, du Developpement Durable et de l'Énergie). Accessed Nov 2013, http://www.hydro.eaufrance.fr.

Ibaibarriaga, L., C. Fernández, A. Uriarte, and B. A. Roel. 2008. A two-stage biomass dynamic model for Bay of Biscay anchovy: a Bayesian approach. ICES Journal of Marine Science: Journal du Conseil 65:191-205.

Ibaibarriaga, L., C. Fernández, and A. Uriarte. 2011. Gaining information from commercial catch for a Bayesian twostage biomass dynamic model: application to Bay of Biscay anchovy. ICES Journal of Marine Science: Journal du Conseil 68:1435-1446.

ICCAT. 2013. Sample fishing statistics and fish sizes: Task II Catch \& Effort Data Base, Nov 2013. www.iccat.int.

ICES. 2012. Report of the Working Group on Southern Horse Mackerel, Anchovy and Sardine (WGHANSA). ICES
CM 2012/ACOM:16, 23-28 June 2012, Azores (Horta), Portugal.

ICES. 2013. Stock Assessment Summary Database, April 2013. www.ices.dk.

Iles, T. D., and M. Sinclair. 1982. Atlantic herring: stock discreteness and abundance. Science 215:627-633.

Irigoien, X., et al. 2007. Could Biscay Bay anchovy recruit through a spatial loophole? Progress in Oceanography $74: 132-148$.

Jackson, J. B. C., et al. 2001. Historical overfishing and the recent collapse of coastal ecosystems. Science 293:629-637.

Kantas, N., A. Doucet, S. S. Singh and J. Maciejowski. 2009. An overview of sequential Monte Carlo methods for parameter estimation on general state space models. in E. Walter, editor. 15th IFAC Symp. Syst. Identification 15 (Saint Malo, France). International Federation of Automatic Control.

Koutsikopoulos, C., and B. Le Cann. 1996. Physical processes and hydrological structures related to the Bay of Biscay anchovy. Scientia Marina 60:9-19.

Le Traon, P. Y., F. Nadal, and N. Ducet. 1998. An improved mapping method of multisatellite altimeter data. Journal of Atmospheric and Oceanic Technology 15:522-534.

Massé, J. 1996. Acoustic observations in the Bay of Biscay: schooling, vertical distribution, species assemblages and behaviour. Scientia Marina 60:227-234.

Mertz, G., and R. A. Myers. 1996. An extended cohort analysis: incorporating the effect of seasonal catches. Canadian Journal of Fisheries and Aquatic Sciences 53:159-163.

Motos, L. 1996. Reproductive biology and fecundity of the Bay of Biscay anchovy population (Engraulis encrasicolus L.). Scientia Marina 60:195-207.

Motos, L., A. Uriarte, and V. Valencia. 1996. The spawning environment of the Bay of Biscay anchovy (Engraulis encrasicolus L.). Scientia Marina 60:117-140.

Peterman, R. M., and M. J. Bradford. 1987. Wind speed and mortality rate of a marine fish, the northern anchovy (Engraulis mordax). Science 235:354-356.

Planque, B., and L. Buffaz. 2008. Quantile regression models for fish recruitment-environment relationships: four case studies. Marine Ecology Progress Series 357:213-223.

Platt, T., C. Fuentes-Yaco, and K. T. Frank. 2003. Spring algal bloom and larval fish survival. Nature 423:398-399.

Reynolds, R. W., T. M. Smith, C. Liu, D. B. Chelton, K. S. Casey, and M. G. Schlax. 2007. Daily high-resolutionblended analyses for sea surface temperature. Journal of Climate 20:5473-5496.

Ricker, W. E. 1954. Stock and recruitment. Journal of the Fisheries Research Board of Canada 11:559-623.

Robert, C. P. 2001. The Bayesian choice. Second edition. Springer Texts in Statistics, New York, New York, USA.

Schaefer, M. B. 1954. Some aspects of the dynamics of populations important to the management of the commercial marine fisheries. Bulletin of the Inter-American Tropical Tuna Comission 1:27-56.

Schnute, J. 1985. A general theory for analysis of catch and effort data. Canadian Journal of Fisheries and Aquatic Sciences 42:414-429.

Shadden, S. C., F. Lekien, and J. E. Marsden. 2005. Definition and properties of Lagrangian coherent structures from finitetime Lyapunov exponents in two-dimensional aperiodic flows. Physica D: Nonlinear Phenomena 212:271-304.

Shelton, A. O., and M. Mangel. 2011. Fluctuations of fish populations and the magnifying effects of fishing. 
Proceedings of the National Academy of Sciences 108:7075-7080

Somarakis, S., I. Palomera, A. Garcia, L. Quintanilla, C. Koutsikopoulos, A. Uriarte, and L. Motos. 2004. Daily egg production of anchovy in european waters. ICES Journal of Marine Science: Journal du Conseil 61: 944-958.

Tuljapurkar, S., C. Boe, and K. W. Wachter. 1994. Nonlinear feedback dynamics in fisheries: analysis of the DerisoSchnute model. Canadian Journal of Fisheries and Aquatic Sciences 51:1462-1473.

Turchin, P. 2003. Complex population dynamics: a theoretical/ empirical synthesis, volume 35 of Monographs in Population Biology. First edition. Princeton University Press, Princeton, New Jersey, USA.

Uriarte, A., P. Prouzet, and B. Villamor. 1996. Bay of Biscay and Ibero Atlantic anchovy populations and their fisheries. Scientia Marina 60:237-255.

Vermard, Y., P. Marchal, S. Mahévas, and O. Thébaud. 2008. A dynamic model of the bay of biscay pelagic fleet simulating fishing trip choice: the response to the closure of the european anchovy (Engraulis encrasicolus) fishery in 2005. Canadian Journal of Fisheries and Aquatic Sciences 65:2444-2453.

Walters, C. J., and D. Ludwig. 1981. Effects of measurement errors on the assessment of stock-recruitment relationships. Canadian Journal of Fisheries and Aquatic Sciences 38:704-710.

Ward, E. J., E. E. Holmes, J. T. Thorson, and B. Collen. 2014. Complexity is costly: a meta-analysis of parametric and non-parametric methods for short-term population forecasting. Oikos 123:652-661.

West, M., and J. Harrison. 1997. Bayesian forecasting and dynamic models. Second edition. Springer Series in Statistics, New York, New York, USA.

Whitehead, P. J. P., G. J. Nelson and T. Wongratana. 1988. Clupeoid fishes of the world (Suborder Clupeoidei; Part II, Engraulididae), volume 7 of FAO species catalogue. FAO, Rome, Italy. http://www.fao.org/docrep/009/t0835e/ t0835e00.htm

\section{SUPPORTING INFORMATION}

Additional supporting information may be found in the online version of this article at http://onlinelibrary.wiley.com/ doi/10.1890/15-0006/suppinfo 